\title{
Gas-Phase Intramolecular Cyclization of Argentinated $\mathrm{N}$-Allylbenzamides
}

\author{
Hezhi Sun, ${ }^{1}$ Yunfeng Chai, ${ }^{2}$ Zhe Jin, ${ }^{1}$ Cuirong Sun, ${ }^{2}$ Yuanjiang Pan ${ }^{1}$ \\ ${ }^{1}$ Department of Chemistry, Zhejiang University, Hangzhou, 310027, Zhejiang, China \\ ${ }^{2}$ College of Pharmaceutical Sciences, Zhejiang University, Hangzhou, 310058, Zhejiang, China
}

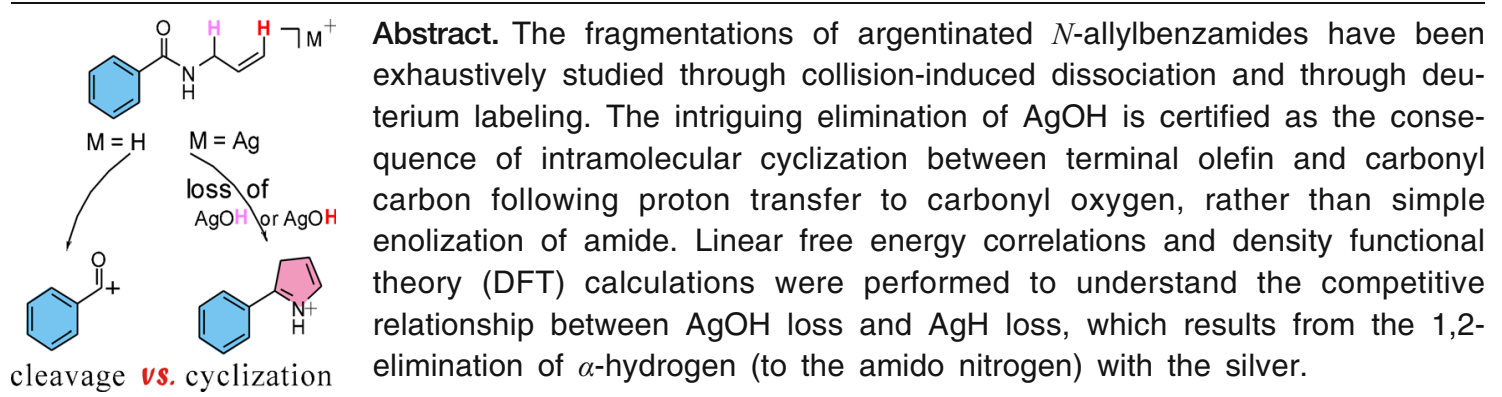

Keywords: Collisional activation, Cyclodehydration, $\mathrm{AgOH}$ loss, $\mathrm{AgH}$ loss, $\mathrm{N}$-allylbenzamide

Received: 5 November 2014/Revised: 20 December 2014/Accepted: 13 January 2015/Published Online: 24 February 2015

\section{Introduction}

$\mathrm{N}$ itrogen-containing heterocycles (NHCs) are frequently present in natural products endowed with biological activities and can be used as versatile building blocks in medicinal chemistry [1], which makes the construction of NHCs an attractive field in organic synthesis. At present, NHCs are most commonly accessed by one of two different methods: ringclosing metathesis of dienes [2-4] or cyclization [5-7], attributable to their facile substrate construction and the relatively mild reaction conditions.

Starting from $\mathrm{N}$-allylbenzamides, a series of NHCs have already been prepared via alternative cyclizations. Intramolecular oxidative cyclization of $\mathrm{N}$-allylbenzamides is widely used to prepare oxazoles [8], whereas atom transfer cyclizations are generally applied in the synthesis of oxazolines [9, 10]. When $\mathrm{N}$-allylbenzamides are treated with chlorinated agents [such as $(\mathrm{PhO})_{3} \mathrm{P}-\mathrm{Cl}_{2}$, and $\mathrm{COCl}_{2}$ ] along with strong bases (such as t$\mathrm{BuOK}$ ), pyrroles are formed via nucleophilic attack of $\alpha$-carbon on imino chlorides [11-13]. Moreover, Pd-catalyzed

Cuirong Sun and Yuanjiang Pan contributed equally to this work.

Electronic supplementary material The online version of this article (doi:10.1007/s13361-015-1079-0) contains supplementary material, which is available to authorized users.

Correspondence to: Yuanjiang Pan; e-mail: panyuanjiang@zju.edu.cn cyclization of $\mathrm{N}$-allyl-2-iodobenzamides is efficient in the synthesis of fused heterocycles, isoquinolin-1-one [14].

Following the rising interest in heterocyclic synthesis, the role of metallic silver in the cyclizations of numerous unsaturated substrates, such as alkenes, alkynes, allenes, and olefins, has changed from an auxiliary (co-catalyst or Lewis acid) into a dominating catalyst [15-18]. To get a deeper insight into the intrinsic mechanisms without the interference of solvent effects or aggregation phenomena, researchers usually turn to mass spectrometry for help, especially electrospray ionization mass spectrometry (ESI-MS) [19-22]. With the high vacuum and feasible interface to the liquid phase, ESI-MS has long served as the gas-phase medium in which to form gaseous key ions and, hence, probe reaction mechanisms and establish intrinsic reactivity orders.

In the gas-phase chemistry of numerous argentinated organic ligands, product ions retaining the silver ion are generally observed [23-27] except when elimination of $\mathrm{AgR}\left(\mathrm{R}=\mathrm{CH}_{3}\right.$, ph) $[27,28]$ or $\mathrm{AgH}$ [24-30] takes place. In the case of argentinated amines, aminocarboxylic acids, ethers, or compounds possessing at least one $\alpha$-hydrogen to the amino nitrogen or ether oxygen, the $\alpha$-hydrogen tends to cleave with the silver in a 1,2-elimination [28-30]. However, in the collisional activations of argentinated chalcones, a distinct AgH loss has been discovered resulting from Oxo-Diels-Alder reaction rather than 1,2-elimination, while a peculiar $\mathrm{AgOH}$ loss is ascertained as the result of Nazarov cyclization [31]. Recently, 
another similar loss has been found in the CID fragmentation of argentinated $\mathrm{N}$-arylmethyl-pyridin-2-ylmethanimine, where one molecular $\mathrm{AgNH}_{2}$ is eliminated as the consequence of intramolecular arylmethyl transfer combined with cyclodeamination [32].

Distinct from the argentinated compounds, the fragmentations of lithiated compounds are much simpler. Generally, product ions retaining the lithium ion are observed [24, 3335]. However, in the dissociations of lithiated aromatic amino acid, histidine and proline, the special elimination of $\mathrm{LiOH}$ has been discovered resulting from the direct cleavage with the hydroxyl group of carboxylic acid [24, 36]. One exceptional $\mathrm{LiOH}$ loss was explored by Guo et al. in the lithiated amides, where the $\mathrm{LiOH}$ is eliminated depending on the occurrence of enolization of amide [37].

In the past decades, silver complexes have shown an efficient catalysis on the intramolecular addition of oxygen and nitrogen nucleophiles to alkynes, allenes, and olefins to generate oxygen and nitrogen heterocycles [15-18]. Yet the intramolecular cyclizations of $N$-allylbenzamide catalyzed by silver have not been investigated either in the gas-phase or solutionphase. In an attempt to access whether the silver cation can promote the cyclization of $\mathrm{N}$-allylbenzamide or not, we devoted our efforts to study the gas-phase chemistry of argentinated $\mathrm{N}$-allylbenzamide. More than highlighting the vital role that the attached cation plays in fragmentation patterns, this research also contributes to the development of intramolecular cyclization.

\section{Experimental}

\section{Chemicals}

The $N$-allylbenzamides, shown in Table 1, were obtained in the same way as in a previous paper [38]. The structures of all compounds were confirmed by ${ }^{1} \mathrm{H}$ and ${ }^{13} \mathrm{C}$ NMR and high resolution mass spectrometry. $N$-allylbenzamide, ${ }^{1} \mathrm{H}$ NMR $\left(500 \mathrm{MHz}, \mathrm{CDCl}_{3}\right): \delta(\mathrm{ppm})=7.79(\mathrm{~d}, 2 \mathrm{H}), 7.48(\mathrm{t}, 1 \mathrm{H})$, $7.40(\mathrm{t}, 2 \mathrm{H}), 6.62(\mathrm{~s}, 1 \mathrm{H}), 5.91(\mathrm{~m}, 1 \mathrm{H}), 5.23(\mathrm{~d}, 1 \mathrm{H}), 5.15(\mathrm{~d}$, $1 \mathrm{H}), 4.06(\mathrm{~s}, 2 \mathrm{H}) ;{ }^{13} \mathrm{C}$ NMR $\left(150 \mathrm{MHz}, \mathrm{CDCl}_{3}\right): \delta(\mathrm{ppm})=$ 167.7, 134.6, 134.3, 131.7, 128.7, 127.2, 116.7, 42.6 .

\section{Mass Spectrometry}

All CID mass spectra were obtained in the positive-ion mode using a Varian (Palo Alto, CA,USA) 500-MS mass spectrometer equipped with an electrospray source and an ion trap analyzer. Dilute methanol solutions containing samples were introduced to the ion source with a syringe pump at a flow rate of $10 \mu \mathrm{L} \mathrm{min}{ }^{-1}$ and relevant parameters were set as follows: spray chamber temperature, $50^{\circ} \mathrm{C}$; drying gas temperature, $350^{\circ} \mathrm{C}$; needle voltage, $5000 \mathrm{~V}$; capillary voltage, $80 \mathrm{~V}$; spray shield voltage, $600 \mathrm{~V}$; rf loading, $85 \%$; scan mode, standard. Nitrogen was used as nebulizing gas at a pressure of $35 \mathrm{psi}$ and drying gas at a pressure of 15 psi. The CID mass spectra were obtained with helium as the collision gas at appropriate collision energy after isolation of the desired precursor ion. Data reported in the article were acquired through a Varian MS Workstation.

All compounds were purified after synthesis and mixed in methanol with one equivalent of silver nitrate aqueous solution. The mixtures were infused with a syringe pump at a flow rate of $180 \mu \mathrm{L} \mathrm{h}^{-1}$ to the mass spectrometer, at a final concentration of approximate $1 \mu \mathrm{g} \mathrm{mL}^{-1}$.

The accurate mass spectrometric experiments (data in Supplementary Table S1) were operated in the positive-ion mode of a TripleTOF 4600 system with a DuoSpray ion source (AB SCIEX, Foster City, CA, USA). The APCI probe of the source was used for fully automatic mass calibration using the Calibrant Delivery System (CDS). A calibration solution matching polarity of ionization was injected during CDS and the mass axis of the TripleTOF 4600 system was correspondingly calibrated in all scan functions used (MS or MS/MS). Solutions were infused from the ESI source at $10 \mu \mathrm{L} \mathrm{min}{ }^{-1}$

Table 1. $N$-Allylbenzamides and Analogues Studied

\begin{tabular}{|c|c|c|c|c|c|}
\hline \multicolumn{3}{|c|}{ Series I } & \multicolumn{3}{|c|}{ Series II } \\
\hline $\mathrm{R}^{2}=$ allyl & $\mathrm{R}^{1}$ & M.W. & $\mathrm{R}^{1}=\mathrm{H}$ & $\mathrm{R}^{2}$ & M.W. \\
\hline 1 & $\mathrm{H}$ & 161 & \multirow{2}{*}{7} & & \multirow{2}{*}{175} \\
\hline 2 & $\mathrm{OCH}_{3}$ & 191 & & & \\
\hline 3 & $\mathrm{NH}_{2}$ & 176 & \multirow{2}{*}{8} & & \multirow{2}{*}{159} \\
\hline 4 & $\mathrm{~F}$ & 179 & & & \\
\hline 5 & I & 287 & \multirow{2}{*}{9} & & \multirow{2}{*}{189} \\
\hline 6 & $\mathrm{CF}_{3}$ & 229 & & & \\
\hline
\end{tabular}



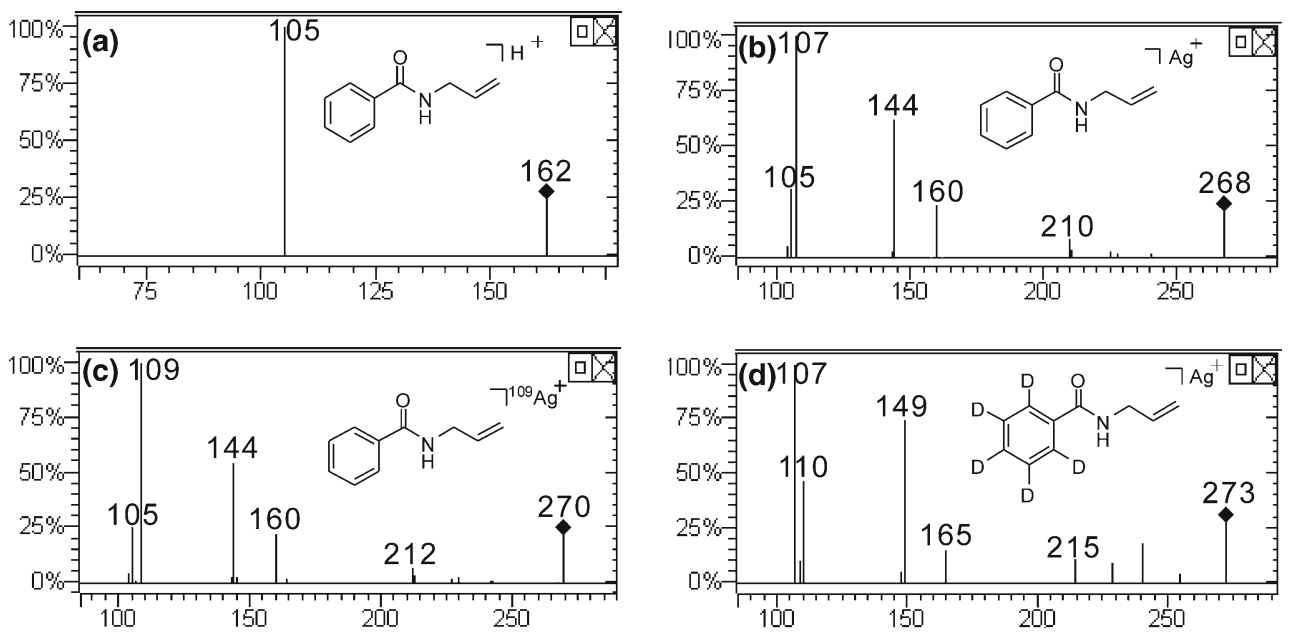

Figure 1. CID mass spectra of (a) protonated $N$-allylbenzamide, (b) $\left[\mathrm{M}+{ }^{107} \mathrm{Ag}\right]^{+}$ion of $N$-allylbenzamide, (c) $\left[\mathrm{M}+{ }^{109} \mathrm{Ag}\right]^{+}$ion of $N^{-}$ allylbenzamide, and (d) $\left[\mathrm{M}+{ }^{107} \mathrm{Ag}\right]^{+}$ion of $N$-allyl-(phenyl- $\left.d_{5}\right)$-methanamide

with the following parameters: ion spray voltage floating, $5500 \mathrm{~V}$; temperature, $550^{\circ} \mathrm{C}$; curtain gas, $25 \mathrm{psi}$, ion source gas, 40 psi. Nitrogen was used both as the curtain gas and ion source gas. The CE was $40 \mathrm{eV}$, and the CES was $15 \mathrm{eV}$ in the MS/MS experiments.

\section{DFT Calculations}

Theoretical calculations were carried out using the Gaussian 03 package of programs [39]. All structures were optimized without symmetry constraints by density functional theory (DFT) using the RB3LYP hybrid method: LANL2DZ basis set for silver while $6-311+\mathrm{G}(d, p)$ basis set for the other atoms. The structures of the two minima associated with each transition state were established by performing intrinsic reaction coordinate (IRC) calculations. The vibrational frequency analysis of all optimized structures was calculated to ensure they corresponded to either true minima (no imaginary frequencies) or transition states (one imaginary frequency). Considering the existence of the weakly bonded interactions involved in this paper, a vibrational frequency scaling factor of 0.967 is applied to the $\mathrm{B} 3 \mathrm{LYP} / 6-311 \mathrm{G}+(d, p)$ harmonic vibrational frequencies, which is taken from the NIST database available on the Internet [40]. Zero-point energies (ZPE) for all the key species were calculated at the same level of theory. The effect of basis set superposition error (BSSE) was analyzed as well by means of the counterpoise correction method. The energies discussed below are the Gibbs free energies.<smiles>[C+]1CCCc2ccccc2C(=C2C=CC=C2)O1</smiles>

$m / z 268$<smiles>C=CC[N+]#Cc1ccccc1</smiles>

$m / z 144$
Scheme 1. Proposed mechanism of AgOH loss resulting from enolization
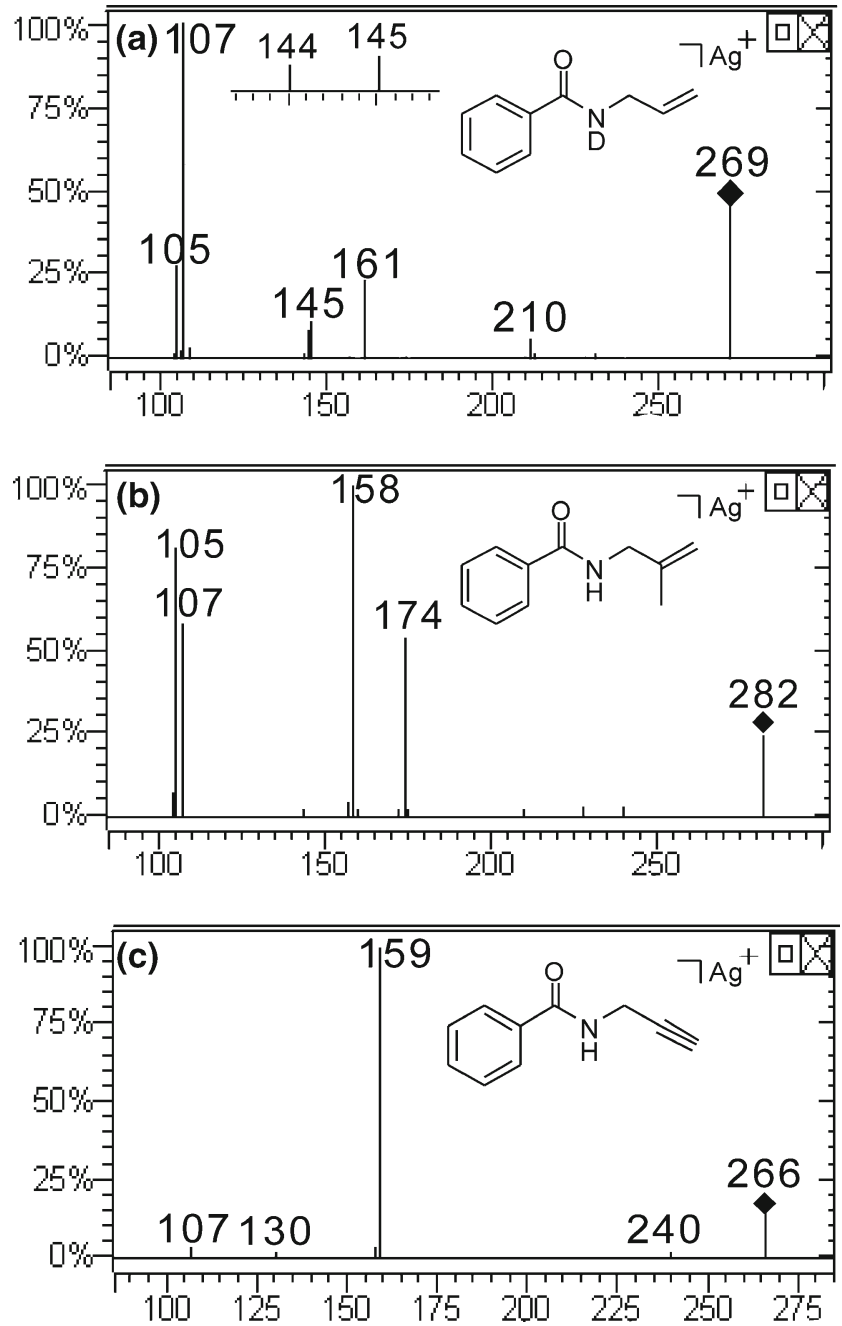

Figure 2. CID mass spectra of $\left[\mathrm{M}+{ }^{107} \mathrm{Ag}\right]^{+}$ion of (a) $N$-allyl, $N$ $d$-benzamide, (b) $\mathrm{N}$-(2-methylallyl)benzamide, and (c) $\mathrm{N}$-(2propynyl)benzamide 


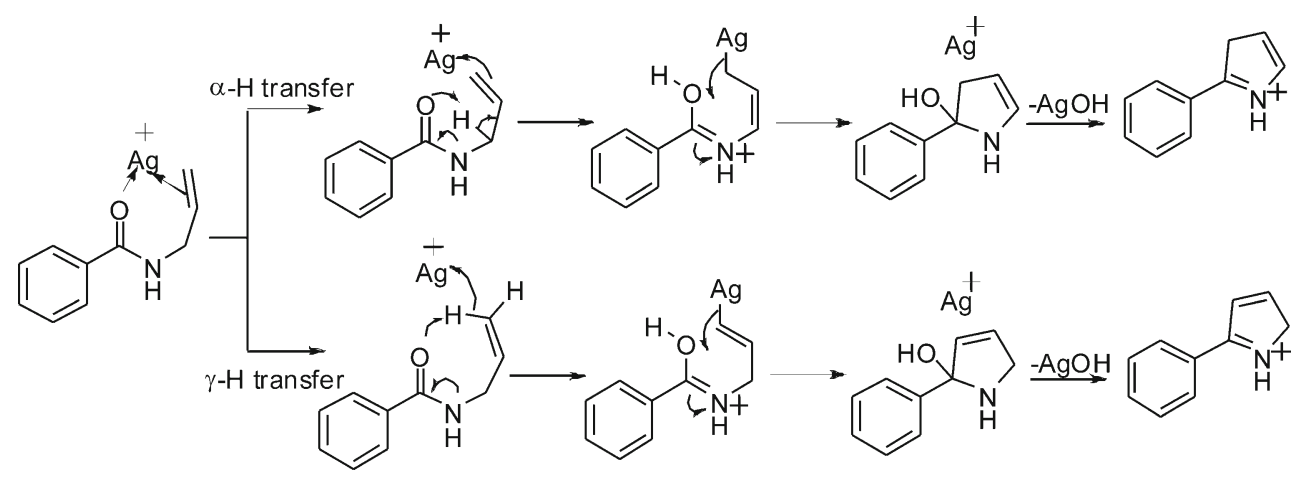

Scheme 2. Proposed mechanism of $\mathrm{AgOH}$ loss from gaseous argentinated $\mathrm{N}$-allylbenzamide

\section{Results and Discussion}

Different from the collisional activation of protonated $\mathrm{N}$ allylbenzamide (Figure 1a), which produces only one fragment ion at $\mathrm{m} / \mathrm{z} 105$ (corresponding to benzoyl cation), the dissociation of argentinated one gave a large number of fragment ions. For a start, all CID mass spectra involving $\mathrm{Ag}^{+}$will be those of the ${ }^{107} \mathrm{Ag}$ isotope except the spectrum in Figure 1c.

By comparing the mass spectrum of $\left[\mathrm{M}+{ }^{109} \mathrm{Ag}\right]^{+}$ion (Figure 1c) with that of $\left[\mathrm{M}+{ }^{107} \mathrm{Ag}\right]^{+}$ion (Figure 1b) of $N$ allylbenzamide, it is easy to tell the argentinated fragment ions from the non-argentinated ones. These two argentinated fragment ions, including silver cation $(\mathrm{m} / \mathrm{z} 107$ and 109) and argentinated benzonitrile $(\mathrm{m} / \mathrm{z} 210$ and 212$)$, are beyond our interest. Among non-argentinated fragment ions, the elimination of $\mathrm{AgOH}$ (ion 1 at $m / z$ 144) and $\mathrm{AgH}$ (ion 2 at $\mathrm{m} / \mathrm{z} 160$ ) were noticeable, together with the conventional formation of benzoyl cation $(\mathrm{m} / \mathrm{z} 105)$. All these fragment ions in Figure $1 \mathrm{~b}$ have been confirmed by the accurate mass determined on a QTOF mass spectrometer (Supplementary Table S1). Figure 1d shows the CID spectrum of the argentinated $N$-allyl-(phenyl$d_{5}$ )-methanamide. A comparison with Figure $1 \mathrm{~b}$ reveals that the deuterium is retained in the non-argentinated ions $(\mathrm{m} / \mathrm{z} 149$ and 165 in Figure 1d), thereby providing incontrovertible evidence that the phenyl hydrogen is not involved in the loss of $\mathrm{AgOH}$ or $\mathrm{AgH}$.

At first glance, the present $\mathrm{AgOH}$ loss from benzamide can be well explained by invoking the enolization (Scheme 1), which has been comprehensively confirmed as the reason for LiOH loss in the gas-phase chemistry of lithiated amide [37]. That is, proton transfer from amido nitrogen to carbonyl oxygen results in the conversion of benzamide to benzimidic acid, and then $\mathrm{AgOH}$ is eliminated.

Unexpectedly, the CID spectrum of argentinated $N$-allyl, $N$ $d$-benzamide shows signals corresponding to the losses of $\mathrm{AgOH}$ and $\mathrm{AgOD}$ (at $\mathrm{m} / \mathrm{z} 145$ and 144 respectively), at an approximate ratio of 1 to 1 (Figure $2 \mathrm{a}$ ). As the deuterium exchange experiment of argentinated $N$-allylbenzamide is not persuasive enough to support the proposal in Scheme 1, the fragmentations of argentinated $N$-(2-methylallyl)benzamide and $N$-(2-propynyl)benzamide were carried out to reveal the underlying mechanism. The signal corresponding to $\mathrm{AgOH}$ loss shows at $m / z 158$ when the allyl group is replaced by 2methylallyl (Figure 2b), but disappears when 2-propynyl is attached on the amido nitrogen instead of allyl (Figure $2 c$, the ion at $\mathrm{m} / \mathrm{z} 159$ corresponding to the loss of silver atom). These results not only exclude the responsibility of enolization for $\mathrm{AgOH}$ loss but also indicate the involvement of allyl group in the process of $\mathrm{AgOH}$ elimination.

On the basis of the present experimental observations and published literature on cyclization of $\mathrm{N}$-allylbenzamides to pyrroles (Supplementary Scheme S1) [11-13], a plausible mechanism is postulated in Scheme 2. After proton transfers (PT, from $\alpha$-site or $\gamma$-site) to carbonyl oxygen, cyclization occurs between olefin and carbonyl carbon, which undergoes the elimination of $\mathrm{AgOH}$ subsequently. Both the intermediates after PT possess two active hydrogens (hydroxyl one and amido one). These two hydrogens are exchangeable with each other by amide-iminol tautomerization, which can well explain the observation in Figure $2 \mathrm{a}$ that the intensity ratio of fragment at $m / z 144$ (AgOD loss) over fragment at $m / z 145$ (AgOH loss) is close to one.

To experimentally certify the cyclization, the CID fragmentation of argentinated $N$-(3-methyl-2-butenyl)benzamide was studied. When the vital reactive site (terminal end of allyl) toward the cyclization is blocked with methyl group, the signal corresponding to $\mathrm{AgOH}$ loss is absent at $\mathrm{m} / \mathrm{z} 172$ (Figure 3). It is clear that the elimination of $\mathrm{AgOH}$ should depend on the occurrence of cyclization instead of enolization.

In addition to tandem mass spectrometry, density functional theory (DFT) calculations, which have been frequently utilized in elucidating the gaseous chemistry of argentinated com-

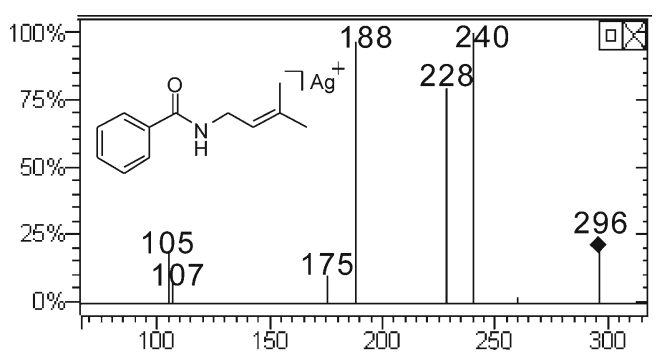

Figure 3. CID mass spectrum of $\left[\mathrm{M}+{ }^{107} \mathrm{Ag}\right]^{+}$ion of $\mathrm{N}-(3-$ methyl-2-butenyl)benzamide 


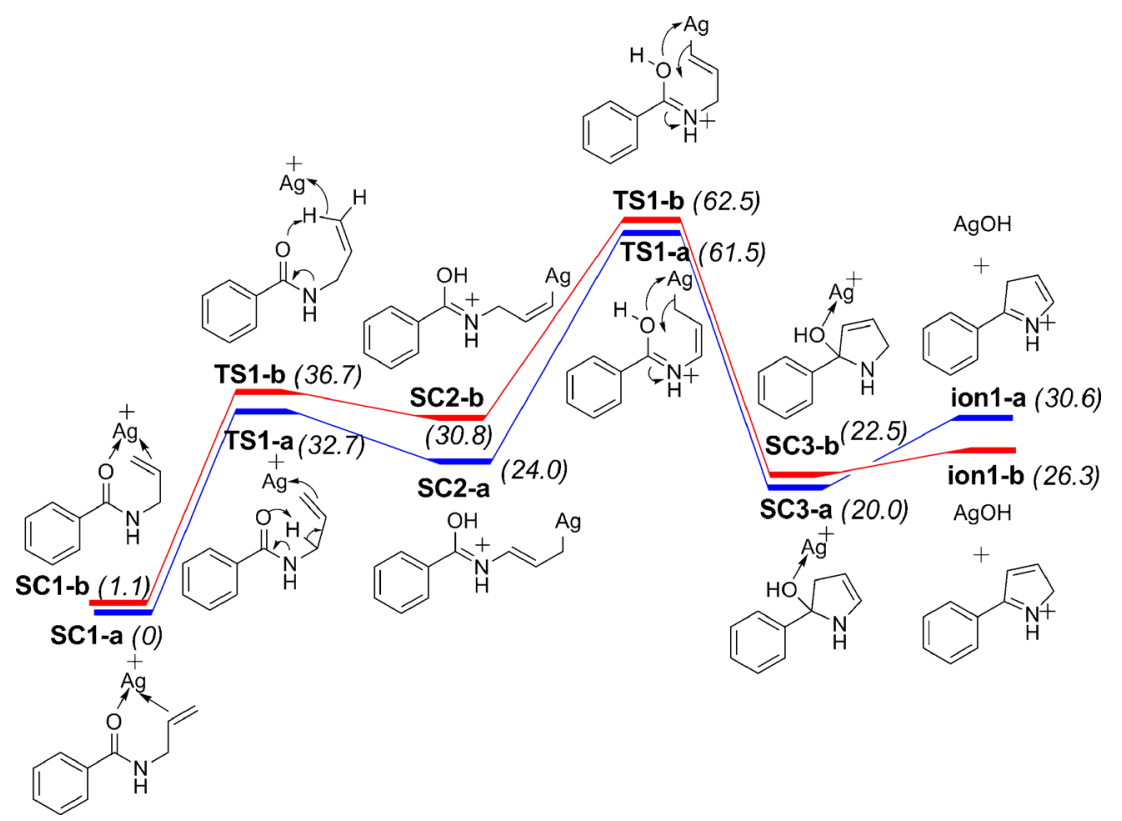

Figure 4. DFT potential energy surfaces of $\gamma$-PT pathway (red line) and $\alpha$-PT pathway (blue line) for AgOH loss

pounds [41, 42], were performed to determine which pathway ( $\alpha$-PT pathway or $\gamma$-PT one) is more favorable for AgOH loss. As shown in Figure 4, the total energy of products from the $\alpha$ PT pathway is $4.3 \mathrm{kcal} \mathrm{mol}^{-1}$ higher than that of the products from the $\gamma$-PT pathway. However, the transition state energy of $\alpha$-PT pathway is below the energy thresholds of $\gamma$-PT pathway by the amount of $1 \mathrm{kcal} \mathrm{mol}^{-1}$. No matter whether considering from the energies of the products or transition states, the energy difference between $\alpha$-PT pathway and $\gamma$-PT pathway is too small to tell which one is dominating.

Nevertheless, DFT calculations do suggest that direct cyclization before proton transfer is inapplicable for $\mathrm{AgOH}$ loss because the energy threshold is $86.5 \mathrm{kcal} \mathrm{mol}^{-1}$ (Supplementary Figure S1) and unachievable in the CID process.

On the other hand, the AgH loss from argentinated $\mathrm{N}$ allylbenzamide (Scheme 3) follows the mechanism common to those argentinated compounds possessing at least one $\alpha$ hydrogen to the amino nitrogen or ether oxygen, where the $\alpha$ hydrogen tends to cleave with the silver in a 1,2-elimination. This proposition is supported by deuterium labeling experiments along with blocking experiments. In deuterium labeling experiments, when the phenyl hydrogen or the amido hydrogen is replaced by the deuterium, no AgD is eliminated $(\mathrm{m} / z 165$ in Figure $1 \mathrm{~d}$ and $m / z 161$ in Figure 2a). Apparently, the hydrogen required for the elimination of $\mathrm{AgH}$ is from the allyl group.

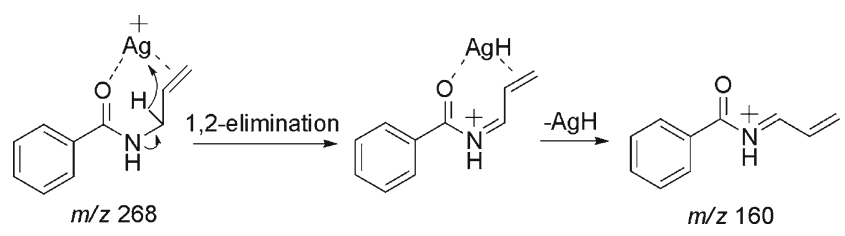

Scheme 3. Proposed mechanism of $\mathrm{AgH}$ loss resulting from 1,2-elimination
Furthermore, when the $\beta$-or $\gamma$-site of allyl is blocked by the methyl group, one molecule of AgH still can be eliminated $(\mathrm{m} / \mathrm{z}$ 174 in Figure $2 \mathrm{~b}$ and $\mathrm{m} / \mathrm{z} 188$ in Figure 3), revealing that the hydrogen required for the elimination of $\mathrm{AgH}$ should originate from the $\alpha$-site.

Comparing the energetic requirement for $\mathrm{AgOH}$ loss (Figure 4) with that for $\mathrm{AgH} \mathrm{[43]} \mathrm{loss} \mathrm{(Figure} \mathrm{5),} \mathrm{the} \mathrm{product} \mathrm{ions}$ arising from AgOH loss (26.3 or $30.6 \mathrm{kcal} \mathrm{mol}^{-1}$ ) are more stable than that from $\mathrm{AgH}$ loss $\left(39.4 \mathrm{kcal} \mathrm{mol}^{-1}\right)$. The transition state energy of $\mathrm{AgOH}$ loss (62.5 or $\left.61.5 \mathrm{kcal} \mathrm{mol}^{-1}\right)$, on the contrary, is above the energy thresholds of $\mathrm{AgH}$ (42.2 $\left.\mathrm{kcal} \mathrm{mol}^{-1}\right)$. Considering the stabilities of product ions, the $\mathrm{AgOH}$ loss from the argentinated $\mathrm{N}$-allylbenzamide is preferred over the AgH loss. However, on the basis of the transition state energy, AgH loss is

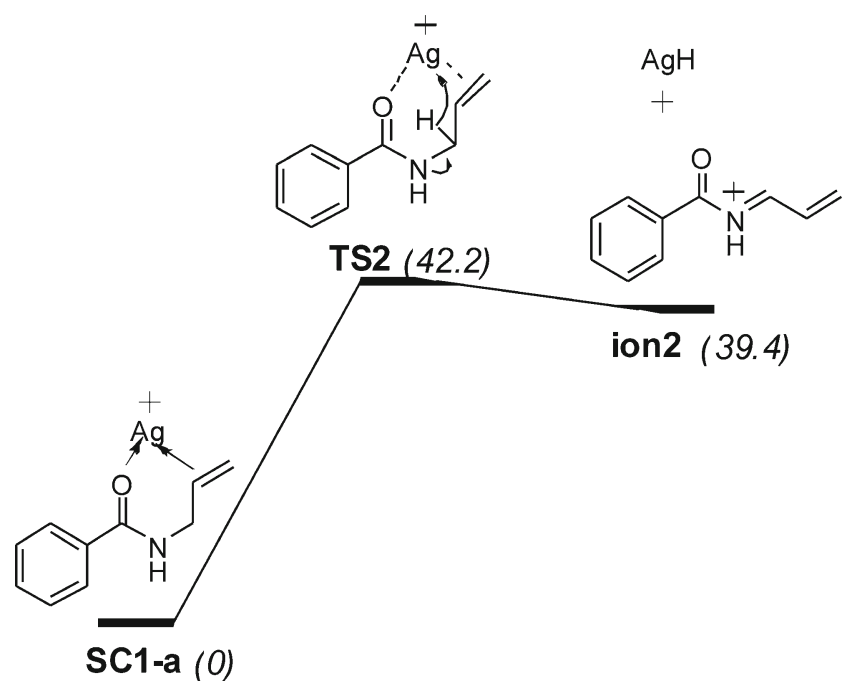

Figure 5. DFT potential energy surfaces of 1,2-elimination of $\mathrm{AgH}$ 


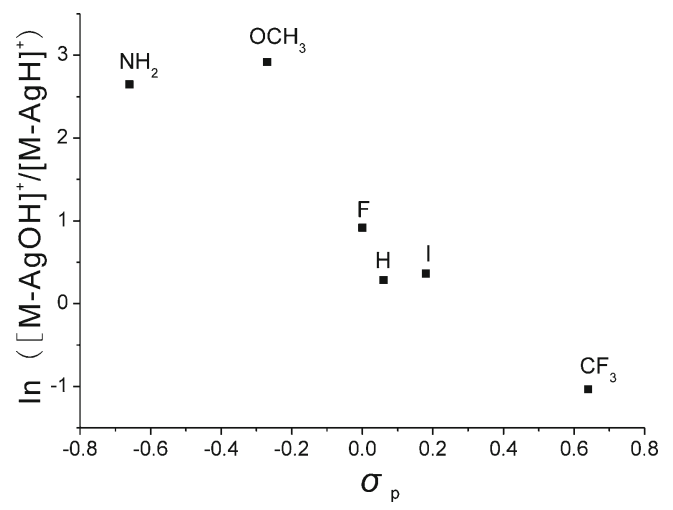

Figure 6. Competition of proton between $\mathrm{AgOH}$ loss and $\mathrm{AgH}$ loss from argentinated $\mathrm{N}$-allylbenzamide with different parasubstituents on the phenyl ring in relation with the $\sigma_{\mathrm{p}}{ }^{+}$substituent constants

more favorable than $\mathrm{AgOH}$ loss. Actually, in the experimental distribution of the product ions (Figure 1b), the abundance of ion $\mathbf{1}$ corresponding to $\mathrm{AgOH}$ loss is much higher than that of ion $\mathbf{2}$ corresponding to $\mathrm{AgH}$ loss, clearly illustrating that the product thermochemistry takes control of the competitive reactions regardless of the transition states.

Linear free energy correlations, one of the most powerful physical organic chemistry tools, have been widely used in the study and interpretation of organic reactions and their mechanisms as well. The relationship was developed by Hammett $[44,45]$ to treat the electronic effect of meta and para substituents on the rates and equilibria of reactions. Its first application in gas phase was conducted by McLafferty in 1959 [46], who found out that the logarithm of the ratio of the fragment ion to the precursor ion increases linearly with the increase in the substituent constants. From then on, Hammett plots have been extensively employed in the study of gas-phase chemistry [47-50] owing to its intuitive presentation of the substituent effect on the direct cleavage as well as on competitive fragmentation pathways. To get a more direct understanding on the relationship between substituents and competitive pathways, the logarithm of the intensity ratios of these two competitive product ions are usually utilized to plot with the substituent constants $[31,37,50,51]$.

In order to enlighten the competitive relationship between $\mathrm{AgOH}$ loss and $\mathrm{AgH}$ loss in present case, linear free energy correlations have been accomplished. The argentinated $N$ allylbenzamide compounds that were monosubstituted at the para position of the phenyl ring underwent similar fragmentation reactions, whereas the relative abundances of the two competing product ions varied as the substituent changed. It was found that electron-donating groups favored the $\mathrm{AgOH}$ loss, whereas the electron-withdrawing groups favored the $\mathrm{AgH}$ loss, as indicated by the relationship of the intensity ratios of these competitive product ions $\left([\mathrm{M}-\mathrm{AgOH}]^{+}\right.$over $[\mathrm{M}-$ $\mathrm{AgH}]^{+}$) with the $\sigma_{\mathrm{p}}^{+}$substituent constants [45] shown in Figure 6. As suggested by the DFT calculations and experimental results, the product thermochemistry takes control of the competition between $\mathrm{AgOH}$ loss and $\mathrm{AgH}$ loss. Therefore, the influence of para-substituents on the product ions dominates over that on the transition states. In view of the structural chemistry, ion $\mathbf{2}$ is insensitive to the para-substituents. By contrast, the stability of ion $\mathbf{1}$ is directly related to the parasubstituent. When an electron-donating group is attached on the para site of the phenyl ring, the positive charge on the nitrogen can be well delocalized for ion 1, which largely stabilizes ion 1 and thus favors the elimination of $\mathrm{AgOH}$. Besides, the electron density of the carbonyl oxygen is elevated at the same time, which makes proton transfer to carbonyl oxygen more easy and, hence, favors the $\mathrm{AgOH}$ loss.

\section{Conclusion}

In short, a significant conclusion from the present work is that compared with the protonation, argentination promotes the cyclization of $\mathrm{N}$-allylbenzamide in the gas phase and leads to a rare elimination of $\mathrm{AgOH}$. The $\mathrm{AgOH}$ loss results from intramolecular cyclization between terminal olefin and carbonyl carbon after proton transfer to carbonyl oxygen. Deuterium labeling experiment and tandem mass spectrometry prove the irrelevance of the phenyl hydrogen and decisive effect of the terminal end of allyl group during the process of $\mathrm{AgOH}$ loss; substituent effect study together with DFT calculations demonstrate that the product thermochemistry takes control of the competition between $\mathrm{AgOH}$ loss and $\mathrm{AgH}$ loss, which arises from the 1,2-elimination of $\alpha$-hydrogen with the silver.

\section{Acknowledgments}

The authors gratefully acknowledge financial support from the National Science Foundation of China (nos. 21025207 and 21372199).

\section{References}

1. O'Hagen, D.: Pyrrole, pyrrolidine, pyridine, piperdine, and tropane alkaloids. Nat. Prod. Rep. 17, 435-446 (2000)

2. Lidwine, C.-L., Bénéteau, V., Joseph, B., Mérour, J.-Y.: Ring closure metathesis of indole 2-carboxylic acid allylamide derivatives. Tetrahedron 58, 10181-10188 (2002)

3. Fu, G.C., Grubbs, R.H.: Synthesis of nitrogen heterocycles via catalytic ring-closing metathesis of dienes. J. Am. Chem. Soc. 114, 7324-7325 (1992)

4. Tasic, G., Simic, M., Popovic, S., Husiec, S., Maslak, V., Savic, V.: Indirect $N$-vinylation of indoles via isomerization of $N$-allyl derivatives: synthesis of (+)-debromoarborescidine B. Tetrahedron Lett. 54, 4536-4539 (2013)

5. Tanaka, K., Tajima, Y.: Transition-metal-catalyzed cyclization of alkynals via oxametallacycle intermediates. Eur. J. Org. Chem. 2012, 3715-3725 (2012)

6. Godoi, B., Schumacher, R.F., Zeni, G.: Synthesis of heterocycles via electrophilic cyclization of alkynes containint heteroactom. Chem. Rev. 111, 2937-2980 (2011)

7. Komeyama, K., Morimoto, T., Takaki, K.: A simple and efficient ioncatalyzed intramolecular hydroamination of unactivated olefins. Angew. Chem. Int. Ed. 45, 2938-2941 (2006)

8. Zhou, W., Xie, C., Han, J., Pan, Y.: Catalyst-free intramolecular oxidative cyclization of $N$-allylbenzamides: a new route to 2,5 -substituted oxazoles. Org. Lett. 14, 4766-4769 (2012)

9. Minakata, S., Morino, Y., Oderaotoshi, Y., Komatsu, M.: Practical and convenient synthesis of $\mathrm{N}$-heterocycles: stereoselective cyclization of $\mathrm{N}$ - 
alkenylamides with t-BuOI under neutral conditions. Org. Lett. 8, 33353337 (2006)

10. Moon, N.G., Harned, A.M.: Iodine(III)-promoted synthesis of oxazolines from $N$-allylamides. Tetrahedron Lett. 54, 2960-2963 (2013)

11. Sessler, J.L., An, D., Cho, W.-S., Lynch, V., Marquez, M.: Calix[n]bispyrrolylbenzenes: synthesis, characterization and preliminary anion binding studies. Chem. Eur. J. 11, 2001-2011 (2005)

12. Spaggiari, A., Vaccari, D., Davoli, P., Prati, F.: The triphenyl phosphatechlorine reagent in the synthesis of pyrroles from $N$-allylamides. Synthesis 6, 995-998 (2006)

13. Engel, N., Steglich, W.: Facile synthesis of 2-aryl- and 2-heteroarylpyrroles from $N$-allylcarboxamides. Angew. Chem. 17, 676-676 (1978)

14. Dhami, A., Mahon, M.F., Lloyd, M.D., Threadgill, M.D.: 4-Substituted 5nitroisoquinolin-1-ones from intramolecular Pd-catalyzed reaction of $\mathrm{N}-(2-$ alkenyl)-2-halo-3-nitrobenzamides. Tetrahedron 65, 4751-4765 (2009)

15. Álvarez-Corral, M., Muñoz-Dorado, M., Rodríguez-García, I.: Silvermediated synthesis of heterocycles. Chem. Rev. 108, 3174-3198 (2008)

16. Naodovic, M., Yamamoto, H.: Asymmetric silver-catalyzed reactions. Chem. Rev. 108, 3132-3148 (2008)

17. Marshall, J.A., Wang, X.: Synthesis of fural by Ag(I)-promoted cyclization of allenyl ketones and aldehydes. J. Org. Chem. 56, 960-969 (1991)

18. Youn, S.W., Eom, J.I.: Ag(I)-catalyzed sequential $\mathrm{C}-\mathrm{C}$ and $\mathrm{C}-\mathrm{O}$ bond formations between phenols and dienes with atom economy. J. Org. Chem. 71, 6705-6707 (2006)

19. Fabris, D.: Mass spectrometric approaches for the investigation of dynamic processes in condensed phase. Mass Spectrom. Rev. 24, 30-54 (2005)

20. Coelho, F., Eberlin, M.N.: The bridge connecting gas-phase and solution chemistries. Angew. Chem. Int. Ed. 50, 5261-5263 (2011)

21. Agrawal, D., Schröder, D.: Insight into solution chemistry from gas-phase experiments. Organometallics 30, 32-35 (2011)

22. Schröder, D.: Applications of electrospray ionization mass spectrometry in mechanistic studies and catalysis research. Acc. Chem. Res. 45, 1521-1532 (2012)

23. Chu, I.K., Shoeib, T., Guo, X., Rodriquez, C.F., Lau, T.-C., Hopkinson, A.C., Siu, K.W.M.: Characterization of the product ions from the collisioninduced dissociation of argentinated peptides. J. Am. Soc. Mass Spectrom. 12, 163-175 (2001)

24. Shoeib, T., Zhao, J., Aribi, H.E., Hopkinson, A.C., Siu, K.W.M.: Dissociations of complexes between monovalent metal ions and aromatic amino acid or histidine. J. Am. Soc. Mass Spectrom. 24, 38-48 (2013)

25. Shoeib, T., Cunje, A., Hopkinson, A.C., Siu, K.W.M.: Gas-phase fragmentation of the $\mathrm{Ag}^{+}$-phenylalanine complex: cation- $\pi$ interactions and radical cation formation. J. Am. Soc. Mass Spectrom. 13, 408-416 (2002)

26. Talaty, E.R., Perera, B.A., Gallardo, A.L., Barr, J.M., Stipdonk, M.J.V.: Elucidation of fragmentation pathways for the collision-induced dissociation of the binary $\mathrm{Ag}(\mathrm{I})$ complex with phenylalanine. J. Phys. Chem. A 105, 8059-8068 (2001)

27. Johnson, B.S., Burinsky, D.J., Burova, S.A., Davis, R., Fitzgerald, R.N., Matsuoka, R.T.: Novel product ions of 2-aminoanilide and benzimidazole $\mathrm{Ag}(\mathrm{I})$ complexes using electrospray ionization with multi-stage tandem mass spectrometry. Rapid Commun. Mass Spectrom. 26, 1115-1122 (2012)

28. Martha, C.T., Zeist, W.-J.V., Bickelhaupt, F.M., Irth, H., Niessen, W.M.A.: Tandem mass spectrometry of silver-adducted ferrocenyl catalyst complexes. J. Mass Spectrom. 45, 1332-1343 (2010)

29. Grewal, R.N., Rodriquez, C.F., Shoeib, T., Chu, I.K., Tu, Y.-P., Hopkinson, A.C., Siu, K.W.M.: Elimination of $\mathrm{AgR}\left(\mathrm{R}=\mathrm{H}, \mathrm{CH}_{3}, \mathrm{C}_{6} \mathrm{H}_{5}\right)$ from collisionally-activated argentinated amines. Eur. J. Mass Spectrom. 6, 187$192(2000)$

30. Schäfer, M., Dreiocker, F., Budzikiewicz, H.: Collision-induced loss of $\mathrm{AgH}$ from $\mathrm{Ag}^{+}$adducts of alkylamines, aminocarboxylic acids, and alkyl benzyl ethers leads exclusively to thermodynamically favored product ions. J. Mass Spectrom. 44, 278-284 (2009)

31. Sun, H., Chai, Y., Wan, L., Jiang, K., Pan, Y.: Nazarov cyclization and Oxo-Diels-Alder reaction of chalcones induced by the naked silver cation in gas phase. Organometallics 32, 3385-3390 (2013)

32. Sun, H., Wang, L., Pan, Y.: Gas-phase arylmethyl transfer and cyclodeamination of argentinated $N$-arylmethyl-pyridin-2-ylmethanimine. J. Am. Soc. Mass Spectrom. 25, 169-175 (2014)

33. Wills, R.H., Tosin, M., O'Connor, P.B.: Structural characterization of polyketides using high mass accuracy tandem mass spectrometry. Anal. Chem. 84, 8863-8870 (2012)
34. Lin, J.-T., Chen, G.Q., Hou, C.T.: Mass spectrometry of the lithium adducts of diacylglycerols containing hydroxy FA in castor oil and two normal FA. J. Am. Oil Chem. Soc. 90, 33-38 (2013)

35. Grossert, J.S., Herrera, L.C., Ramaley, L., Melanson, J.E.: Studying the chemistry of cationized triacylglycerols using electrospray ionization mass spectrometry and density functional theory computations. J. Am. Soc. Mass Spectrom. 25, 1421-1440 (2014)

36. Mookherjee, A., Armentrout, P.B.: Theoretical investigation and reinterpretation of the decomposition of lithiated proline and $N$-methyl proline. Int. J. Mass Spectrom. 370, 16-28 (2014)

37. Guo, C., Zhou, Y., Liu, P., Chai, Y., Pan, Y.: Gas phase chemistry of $\mathrm{Li}^{+}$ with amide: the observation of LiOH loss in mass spectrometry. J. Am. Soc. Mass Spectrom. 23, 1191-1201 (2012)

38. Wang, L., Liu, C., Bai, R., Pan, Y., Lei, A.: Easy access to enamides: a mild nickel-catalyzed alkene isomerization of allylamides. Chem. Commun. 49, 7923-7925 (2013)

39. Frisch, M.J., Trucks, G.W., Schlegel, H.B., Scuseria, G.E., Robb, M.A., Cheeseman, J.R., Montgomery Jr., J.A., Vreven, T., Kudin, K.N., Burant, J.C., Millam, J.M., Iyengar, S.S., Tomasi, J., Barone, V., Mennucci, B., Cossi, M., Scalmani, G., Rega, N., Petersson, G.A., Nakatsuji, H., Hada, M., Ehara, M., Toyota, K., Fukuda, R., Hasegawa, J., Ishida, M., Nakajima, T., Honda, Y., Kitao, O., Nakai, H., Klene, M., Li, X., Knox, J.E., Hratchian, H.P., Cross, J.B., Adamo, C., Jaramillo, J., Gomperts, R., Stratmann, R.E., Yazyev, O., Austin, A.J., Cammi, R., Pomelli, C., Ochterski, J.W., Ayala, P.Y., Morokuma, K., Voth, G.A., Salvador, P., Dannenberg, J.J., Zakrzewski, V.G., Dapprich, S., Daniels, A.D., Strain, M.C., Farkas, O., Malick, D.K., Rabuck, A.D., Raghavachari, K., Foresman, J.B., Ortiz, J.V., Cui, Q., Baboul, A.G., Clifford, S., Cioslowski, J., Stefanov, B.B., Liu, G., Liashenko, A., Piskorz, P., Komaromi, I., Martin, R.L., Fox, D.J., Keith, T., Al-Laham, M.A., Peng, C.Y., Nanayakkara, A., Challacombe, M., Gill, P.M.W., Johnson, B., Chen, W., Wong, M.W., Gonzalez, C., Pople, J.A.: Gaussian 03, Revision B. Gaussian, Inc., Pittsburgh, PA (2003)

40. NIST Computational Chemistry Comparison and Benchmark DataBase, NIST Standard Reference Database Number 101, August 2011, Eds. Russell, D., Johnson, I. I. I., Eds., available at http:// cccbdb.nist.gov/Accessed. Accessed December 20, 2014

41. Rodriquez, C.F., Shoeib, T., Chu, I.K., Siu, K.W.M., Hopkinson, A.C.: Comparison between protonation, lithiation, and argentination of 5oxazolones: a study of a key intermediate in gas-phase peptide sequencing. J. Phys. Chem. A 140, 5325-5342 (2000)

42. Deng, H., Kebarle, P.: Binding energies of silver ion-ligand, L, complexes $\mathrm{AgL}_{2}^{+}$determined from ligand-exchange equilibria in the gas phase. $\mathrm{J}$. Phys. Chem. A 102, 571-579 (1998)

43. Seto, J.Y., Morbi, Z., Charron, F., Lee, S.K., Bernath, P.F., Roy, R.J.L.: Vibration-rotation emission spectra and combined isotopomer analyses for the coinage metal hydrides: $\mathrm{CuH} \& \mathrm{CuD}, \mathrm{AgH} \& \mathrm{AgD}$, and $\mathrm{AuH} \& \mathrm{AuD}$. J. Chem. Phys. 110, 11756-11767 (1999)

44. Hammett, L.P.: The effect of structure upon the reactions of organic compounds benzene derivatives. J. Am. Chem. Soc. 59, 96-103 (1937)

45. Hansch, C., Lwo, A., Tatf, R.W.: A Survey of Hammett substituent constants and resonance and field parameters. Chem. Rev. 91, 165-195 (1991)

46. McLafferty, F.W.: Prediction of mass spectra from substituent constants. Anal. Chem. 31, 477 (1959)

47. Harrison, A.G.: Linear free energy correlations in mass spectrometry. J. Mass Spectrom. 34, 577-589 (1999)

48. Lioe, H., O'Hair, R.A.J.: Neighboring group processes in the deamination of protonated phenylalanine derivatives. Org. Biomol. Chem. 3, 3618$3628(2005)$

49. Vikse, K.L., Henderson, M.A., Oliver, A.G., McIndoe, J.S.: Direct observation of key intermediates by negative-ion electrospray ionization mass spectrometry in palladium-catalyzed cross-coupling. Chem. Commun. 46, $7412-7414$ (2010)

50. Fiebig, L., Schlörer, N., Schmalz, H.-G., Schäfer, M.: Aryl-phenyl scrambling in intermediate organopalladium complexes: a gas-phase study of the Mizoroki-Heck reaction. Chem. Eur. J. 20, 4906-4910 (2014)

51. Hu, N., Tu, Y.-P., Liu, Y., Jiang, K., Pan, Y.: Dissociative protonation and proton transfer: fragmentation of $\alpha, \beta$-unsaturated aromatic ketones in mass spectrometry. J. Org. Chem. 73, 3369-3376 (2008) 